This item was submitted to Loughborough's Research Repository by the author.

Items in Figshare are protected by copyright, with all rights reserved, unless otherwise indicated.

\title{
Suspension polymerisation of vinyl chloride in presence of ultra fine filler
} particles

\section{PLEASE CITE THE PUBLISHED VERSION}

PUBLISHER

Maney Publishing / ( ) Institute of Materials, Minerals and Mining

VERSION

VoR (Version of Record)

LICENCE

CC BY-NC-ND 4.0

\section{REPOSITORY RECORD}

Georgiadou, Stella, Noreen L. Thomas, Marianne Gilbert, and Brian W. Brooks. 2009. "Suspension Polymerisation of Vinyl Chloride in Presence of Ultra Fine Filler Particles". figshare. https://hdl.handle.net/2134/4326. 
This item was submitted to Loughborough's Institutional Repository (https://dspace.lboro.ac.uk/) by the author and is made available under the following Creative Commons Licence conditions.

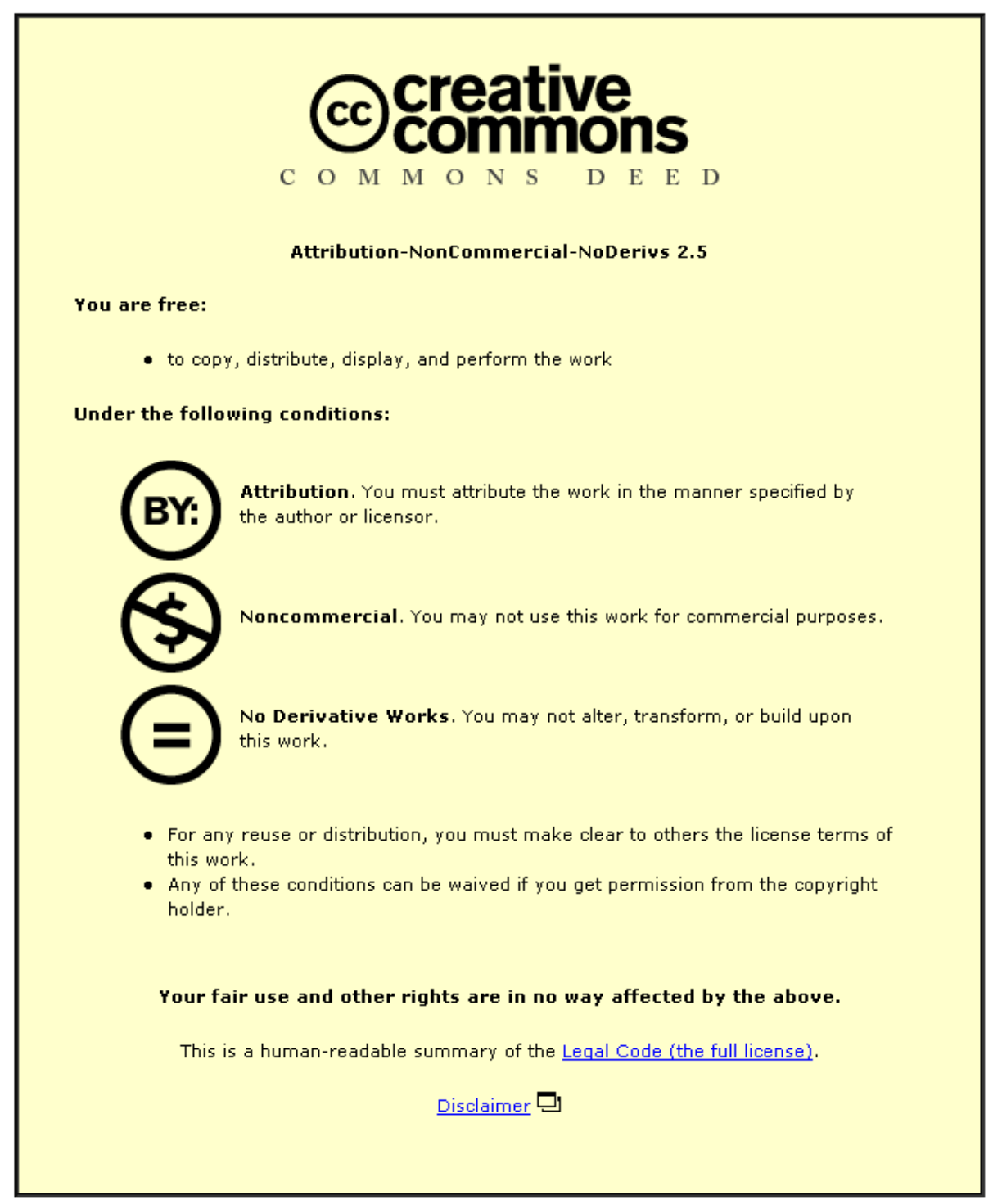

For the full text of this licence, please go to: http://creativecommons.org/licenses/by-nc-nd/2.5/ 


\title{
Suspension polymerisation of vinyl chloride in presence of ultra fine filler particles
}

\author{
S. Georgiadou ${ }^{1}$, N. L. Thomas ${ }^{1}$, M. Gilbert ${ }^{1}$ and B. W. Brooks*2
}

Polymer composites, filled with ultra fine particulate fillers, are alternatives to the conventional filled polymers. The reinforcement of the mechanical properties occurs to a greater extent when ultra fine particulate fillers are used in comparison with the conventional microdimensional fillers. To achieve all the benefits that the ultra fine fillers can provide, optimal dispersion as primary particles is essential. To achieve better dispersion of the inorganic particles in a polymer matrix, the ultra fine particles (UFP) are added to the polymerisation reactor so that they are dispersed in the monomer before polymerisation. Hence, the monomer is polymerised in the presence of the UFP (in situ). In this paper the effects of the UFP on the initial monomer dispersion are examined. The presence of the inorganic UFP in the polymerisation reactor influences the properties of the monomer phase and affects the drop size distribution. This in turn influences the grain sizes as well as their distribution, which influence the processability of the resin.

Keywords: Ultra fine fillers, PVC, $\mathrm{CaCO} 3$ composites, Liquid-liquid dispersion, Suspension polymerisation

\section{Introduction}

Suspension polymerisation in the presence of inorganic ultra fine particles (UFP) has received attention lately as a method to optimise dispersion of the fillers in the polymer matrix and to achieve all the benefits that ultra fine particle fillers can provide, ${ }^{1}$ like higher tensile strength and modulus and increased grain porosity. ${ }^{2}$ $\mathrm{CaCO}_{3}$ UFP were found to stiffen and toughen PVC, ${ }^{3}$ and to influence both the processing and mechanical properties of $\mathrm{PVC}^{4}$ significantly. The presence of the inorganic ultra fine fillers in the polymerisation reactor also influences the shape of the grain and its structure. ${ }^{5}$

The dispersion of the UFP in the monomer phase determines to a great extent the dispersion of the UFP in the polymer matrix. To achieve optimum UFP dispersion in the polymer matrix, optimum dispersion in the monomer phase is required. As the UFP are dispersed in the monomer phase, they influence its properties, the drop formation mechanism and consequently the initial drop size distribution of the monomer - dispersed phase. This in turn influences the PVC grain sizes and their distribution, which eventually influences the resin processability. In suspension polymerisation processes, the combined action of stirring and the use of a suspending agent disperse the monomer in the aqueous phase to form a liquid-liquid dispersion. The monomer drops are subject to shear stresses and to turbulent velocity and pressure variations at the liquid/liquid

${ }^{1}$ IPTME, Loughborough University, Loughborough, Leicestershire, LE11 3TU, UK

${ }^{2}$ Chemical Engineering Department, Loughborough University, Loughborough, Leicestershire, LE11 3TU, UK

*Corresponding author, email B.W.Brooks@ Iboro.ac.uk interface. These processes deform the drops and cause them to break up. At the same time, collision of these drops may lead to coalescence. The drops break up and coalesce until a dynamic steady state is reached, where the breakage and coalescence rates are equal. That steady state condition determines the size of the drops which in turn determine the particle size of the final resin. The eventual drop size depends on factors such as the stirring speed, ${ }^{6}$ the suspending agent concentration ${ }^{7}$ and the viscosity of the two phases, monomer and aqueous phase. The presence of the UFP in the reactor is expected to affect this steady state because it can affect the viscosity of the liquid phases and the drop coalescence. ${ }^{8}$ As a result, the drop and grain sizes and their distribution are expected to be affected. In this work, the authors attempt to examine the way the UFP are dispersed in the monomer phase and how they affect the drop size distribution of the initial monomer dispersion.

\section{Materials}

The vinyl chloride (VC) monomer was supplied by Ineos ChlorVinyls. Polyvinyl alcohol (PVA) with hydrolysis degree $72 \cdot 5 \%$ was used as a suspending agent. Commercial grades of $\mathrm{CaCO}_{3}$ were used for the dispersion and suspension polymerisation experiments, one grade with average particle diameter $<100 \mathrm{~nm}$ and one grade with average diameter $>100 \mathrm{~nm}$. Both of them are precipitated and coated with stearic acid. Perkadox 16 was used as initiator for the polymerisation experiments. Toluene and trichloroethylene were used for the liquid-liquid dispersion experiments, purchased from Aldrich. 

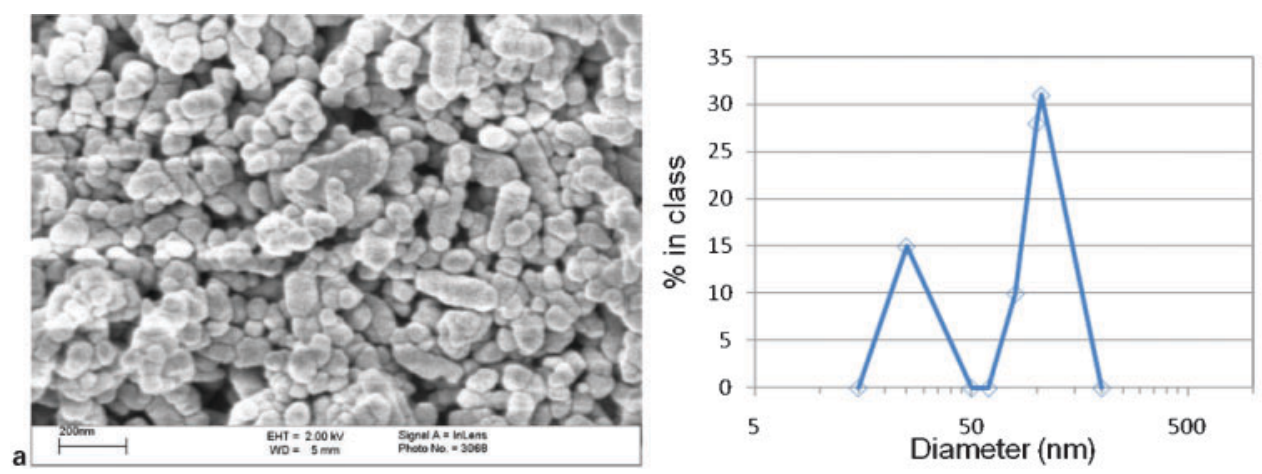

1 a SEM graph and $b$ particle size distribution of $\mathrm{CaCO}_{3}$ UFP with average size $<100 \mathrm{~nm}$

\section{Experimental}

Dispersion and suspension polymerisation experiments were run using a $1 \mathrm{~L}$ stainless steel reactor equipped with three equidistant baffles and a four flat bladed stirrer. The drop size distributions of the dispersions and the grain size distributions of the PVC were measured using a laser diffraction particle sizer.

For the dispersion experiments, the organic - dispersed phase was either toluene or trichloroethylene, which was used as substitutes for VC. The UFP of $\mathrm{CaCO}_{3}$ were first added in the organic phase and stirred. Then a PVA solution was added to the reactor and the mixture was stirred to disperse the organic phase in the aqueous one.

For the suspension polymerisation experiments the UFP of $\mathrm{CaCO}_{3}$ where dispersed in the monomer before polymerisation. $\mathrm{CaCO}_{3} \mathrm{UFP}$ and the initiator were initially charged in the reactor and the reactor was sealed. The reactor was then purged with nitrogen to remove oxygen. The monomer was charged in the reactor next and the mixture was stirred for $30 \mathrm{~min}$ at ambient temperature to dissolve the initiator and disperse the $\mathrm{CaCO}_{3}$ particles. The suspending agent (PVA) solution and deionised water were added last in the reactor after being also treated with nitrogen to remove oxygen. The concentration of the PVA solution was $0 \cdot 3 \% \mathrm{ww}$ in the organic phase for both dispersion and suspension experiments. The mixture was then stirred for $30-40 \mathrm{~min}$ to allow for the PVA molecules to stabilise the monomer drops. The temperature was then raised to $55^{\circ} \mathrm{C}$. The polymerisation was quenched after the pressure in the reactor dropped by 3 bar; that corresponds approximately to a conversion of $80 \%$.

\section{Results and discussion Dispersion of $\mathrm{CaCO}_{3}$ particles}

The improvement of the polymer properties depends, amongst other things, on the adhesion of the polymer to the filler particles. Fine particles exhibit a strong tendency to aggregate and form agglomerates, which usually trap gas between the particles. When the agglomerates are incorporated into the polymer matrix, the trapped gas inhibits the adhesion of the polymer to the particles and, as a result, the agglomerates act as crack initiation points. The enhancement of the polymer properties depends on the efficient and effective dispersion of the fine particles in the polymer matrix.

To achieve optimum fine particle dispersion in the polymer matrix, optimum particle dispersion in the monomer is required. In this case the particles are mixed with the monomer before polymerisation and the mixture is stirred to break down the particle agglomerates. Stirring provides the shear stresses that compete with the attractive forces that hold the agglomerates together and cause the particles to disintegrate. The extent of the disintegration and therefore of the dispersion of the particles is dependant on stirring time and stirring speed. To determine the conditions required for optimum dispersion of the particles before polymerisation, dispersion experiments were performed where trichloroethylene and toluene were used as substitutes for the monomer. It is necessary to determine the minimum stirring time required to disperse the particles because the initiator decomposition, which starts to occur as soon as it is mixed with the monomer, is not desirable before the polymerisation starts.

The dispersion of the particles was determined by measuring the average particle sizes and their distribution at regular time intervals using a Malvern Zetasizer. Figure 1 shows the $\mathrm{CaCO}_{3}$ particles (Fig. 1a) and their size distribution in toluene (Fig. 1b). The particle size distribution of $\mathrm{CaCO}_{3}$ was also measured in trichloroethylene to verify that the dispersion medium did not affect the deagglomeration of the particles. The results and average sizes were the same in both solvents and hence only one of the two solvents is presented here. Figure 2 depicts the average sizes of particle agglomerates during the dispersion process in trichloroethylene with increasing stirring time for various speeds. The average particle agglomerate size decreases initially with increasing stirring time and then reaches a plateau and no further size reduction occurs with increasing time of stirring. The time at the beginning of the plateau is the minimum stirring time required at each stirring speed. For $300 \mathrm{rev} \mathrm{min}^{-1}$, the particles do not seem to deagglomerate, as the average sizes measured correspond to agglomerates rather than primary particles. For $500 \mathrm{rev} \mathrm{min}^{-1}$, dispersion occurs after $40 \mathrm{~min}$ of

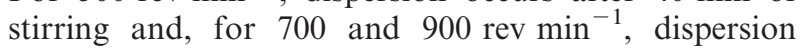
occurs at $\sim 30 \mathrm{~min}$ of stirring. Consequently, the $\mathrm{CaCO}_{3}$ particles together with the initiator are stirred at $700 \mathrm{rev} \mathrm{m^{-1 }}$ for $30 \mathrm{~min}$ before polymerisation to optimise dispersion. 


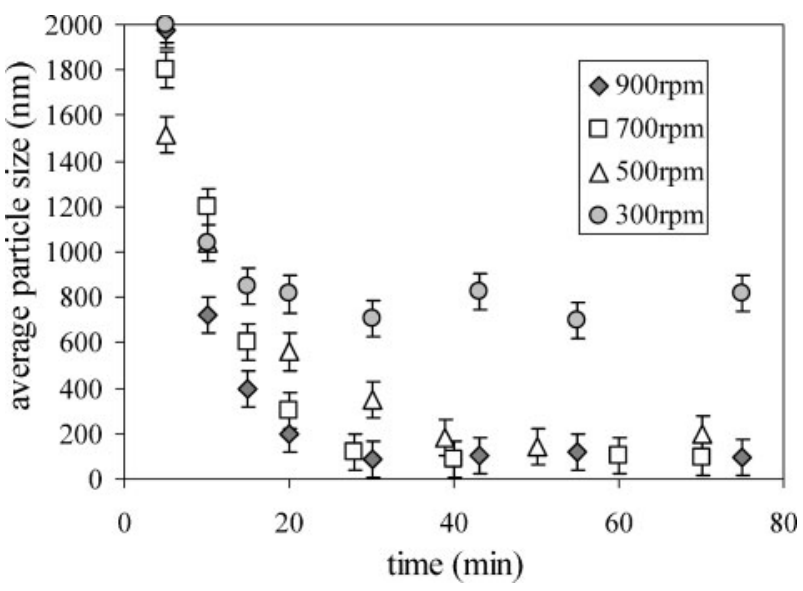

2 Deagglomeration of particles in trichloroethylene with increasing stirring time

\section{Effect of $\mathrm{CaCO}_{3}$ particles on drop size distribution}

In suspension polymerisation the initial dispersion of the organic phase in water is critical as the drop sizes determine the sizes of the final polymer particles. A very common problem encountered in suspension polymerisation processes is the formation of fine polymer particles with diameters within the range of $0 \cdot 1-10 \mu \mathrm{m}$. The formation of these particles has been attributed to various factors. One of the factors that can cause the formation of fine drops/particles is the drop breakage which can occur via an erosive mechanism leading to the formation of fine (satellite) drops. Another reason for the formation of fine particles is the occurrence of emulsion polymerisation simultaneously with the suspension. The initiator can be partially dissolved in water and a small fraction of radicals that are dissolved in water can initiate emulsion polymerisation which leads to fine particles. The formation of fine particles is not desirable as they are separated and removed from the final product. To determine how the addition of inorganic particles affects the initial drop dispersion of the organic phase in water, dispersion experiments were performed, where an organic phase (toluene or toluene $\left.+\mathrm{CaCO}_{3}\right)$ is dispersed in water containing $0 \cdot 3 \%$ ww PVA. In Fig. 3, the drop size distributions of the two aqueous dispersions, with toluene and with toluene $+5 \%$ ww $\mathrm{CaCO}_{3}$, are compared.

The drop size distribution of the organic phase consisting of $\mathrm{CaCO}_{3}+$ toluene is shifted towards larger

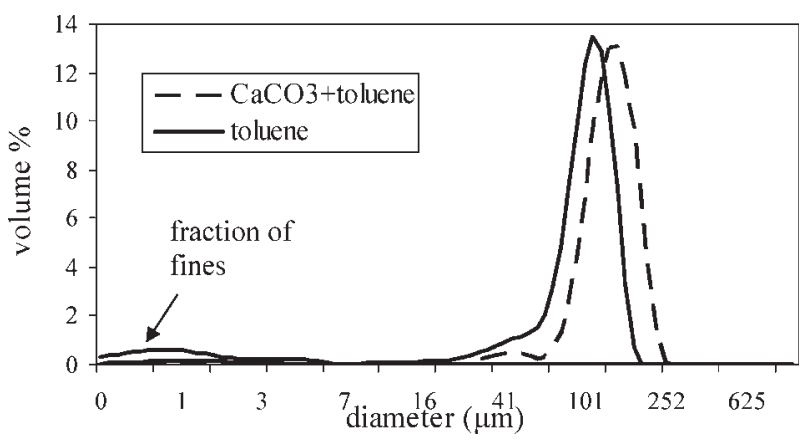

3 Drop size distributions of toluene alone and of toluene $+\mathrm{CaCO}_{3}$ particles with average diameter $<100 \mathrm{~nm}$

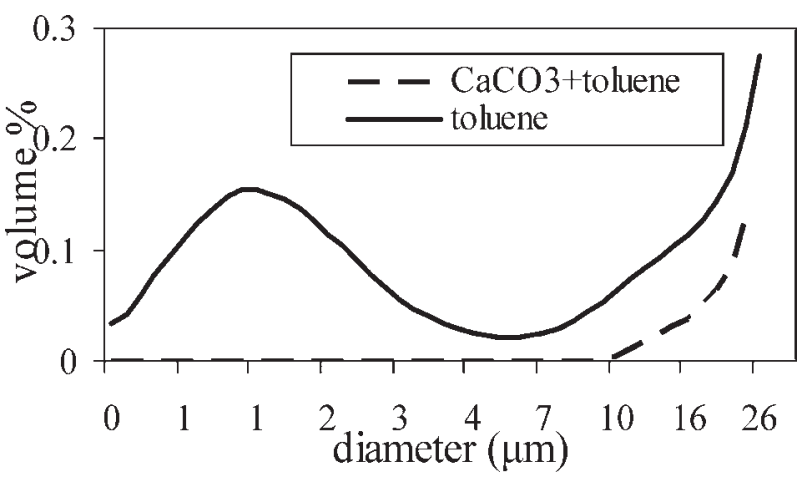

4 Effect of $\mathrm{CaCO}_{3}$ on formation of fine drops/particles

sizes and is slightly wider than the one corresponding to toluene alone. It is also observed that for the toluene dispersion a small fraction of fine drops is formed. The fine drops are depicted in Fig. 4, where it can be observed that the fine drops only appear in the case of toluene but they do not appear when $\mathrm{CaCO}_{3}$ particles are added in the organic phase. The addition of the $\mathrm{CaCO}_{3}$ seems to eliminate the formation of fine drops.

It can be concluded that the addition of $\mathrm{CaCO}_{3}$ fine particles affects the main drop size distribution as it causes the formation of bigger drops, but at the same time it eliminates the formation of fine drops which lead to non-desirable fine polymer particles. These two observations, the increase in the drop size and the elimination of the fine drops, could probably be explained by an increase in the viscosity of the organic phase caused by the addition of the $\mathrm{CaCO}_{3}$ particles. Such an increase in the viscosity could lead to wider drop size distributions. An increase in the viscosity would also render the drops less susceptible to erosion (in the case of erosive drop breakage) and more prone to coalescence, which means that fewer fine drops would form or become stable.

Suspension polymerisation experiments of $\mathrm{VC}$ in the presence of $\mathrm{CaCO}_{3}$ UFP with average size $<100 \mathrm{~nm}$, $5 \% \mathrm{ww} / \mathrm{VC}$, were performed to verify whether the fraction of fine polymerised VC drops is reduced or eliminated in the presence of UFP. The polymerisation experiments where performed following the process described in the experimental part where the $\mathrm{CaCO}_{3}$ UFP were predispersed in the monomer. Figure 5 depicts the particle size distributions of PVC particles produced in the presence of $\mathrm{CaCO}_{3}$ in comparison with pristine PVC particles. It can be observed that the size

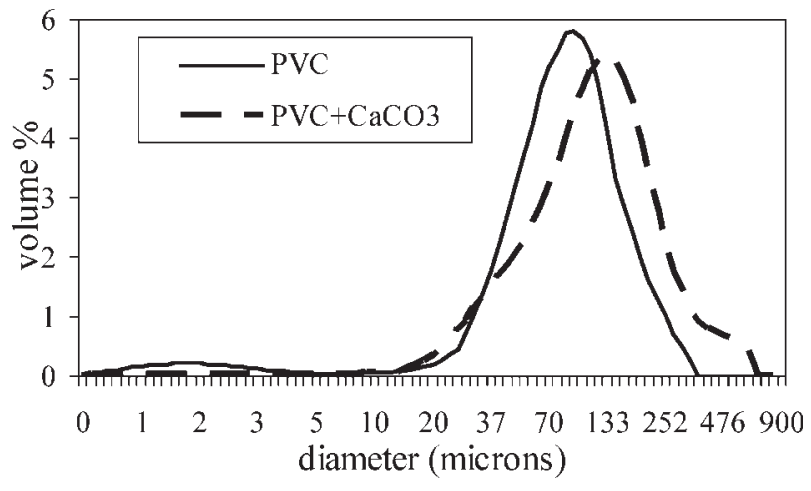

5 Particle size distributions of $\mathrm{PVC}$ and $\mathrm{PVC}+\mathrm{CaCO}_{3}$ UFP $<100 \mathrm{~nm}$ 


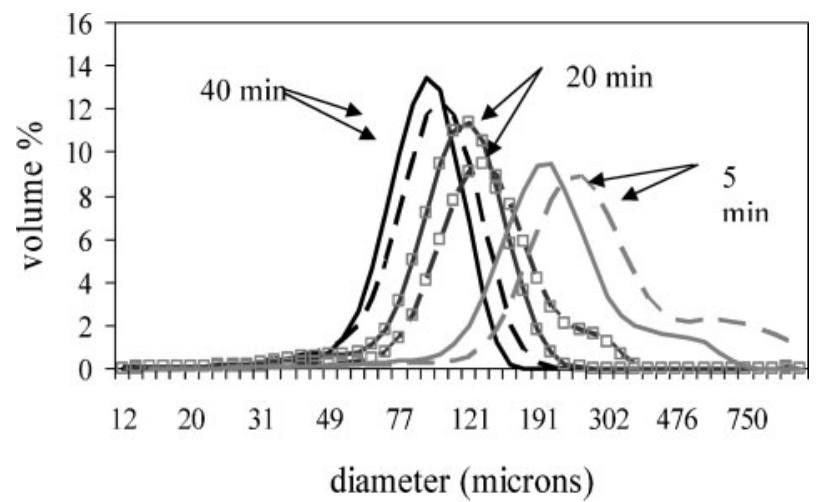

6 Comparison of evolution of drop size distributions of toluene (bulk line) with toluene $+\mathrm{CaCO}_{3}<\mathbf{1 0 0} \mathrm{nm}$ (dotted line)

distribution of the $\mathrm{PVC}+\mathrm{CaCO}_{3}$ particles differs from the particle size distribution of PVC as it is wider and shifted towards larger sizes. Also the fraction of fine particles that is observed in the case of PVC seems to be eliminated for the $\mathrm{PVC}+\mathrm{CaCO}_{3}$ distribution, verifying the initial observation made for the liquid-liquid dispersions.

\section{Evolution of drop size distribution in presence of $\mathrm{CaCO}_{3}$}

In liquid-liquid dispersions, the drop size distribution evolves with time until a dynamic steady state is reached. The drops break up and coalesce continuously and the drop size distribution changes continuously until a dynamic steady state is reached where the drop sizes remain constant. The drop stabilisation is associated with a decrease in the interfacial tension between the monomer and water which is caused by the saturation of the interface with suspending agent molecules and the arrangement of the suspending agent molecules in such a way so that a favourable formation is achieved and the interfacial tension is minimised. Dispersion experiments were performed with toluene and toluene $+5 \% \mathrm{CaCO}_{3}$ to find out what is the effect of $\mathrm{CaCO}_{3}$ on the time evolution of the drop size distribution. In Fig. 6, it can be seen that the evolution of the drop size distribution is influenced by the inorganic particles, as well as the time required for the dynamic steady state to be reached.

For the toluene dispersion the dynamic steady state was reached after $30 \mathrm{~min}$ whereas for the toluene $+\mathrm{CaCO}_{3}$ dispersion the dynamic steady state

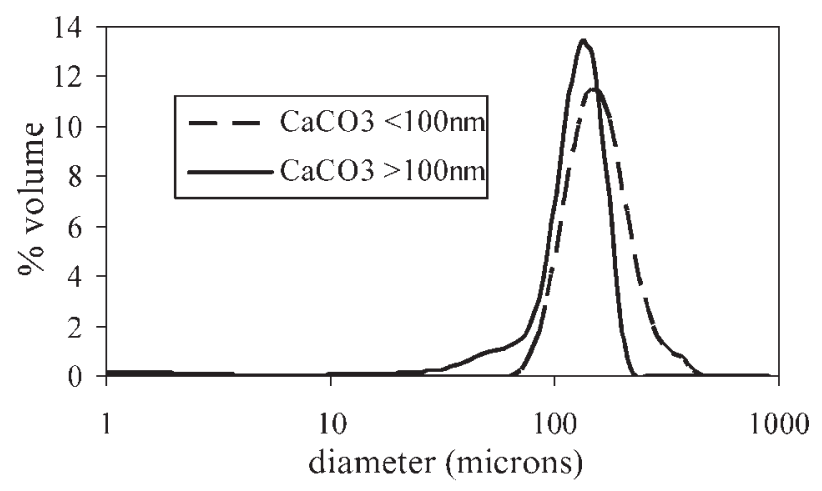

7 Effect of $\mathrm{CaCO}_{3}$ particle size on drop size distribution of trichloroethylene

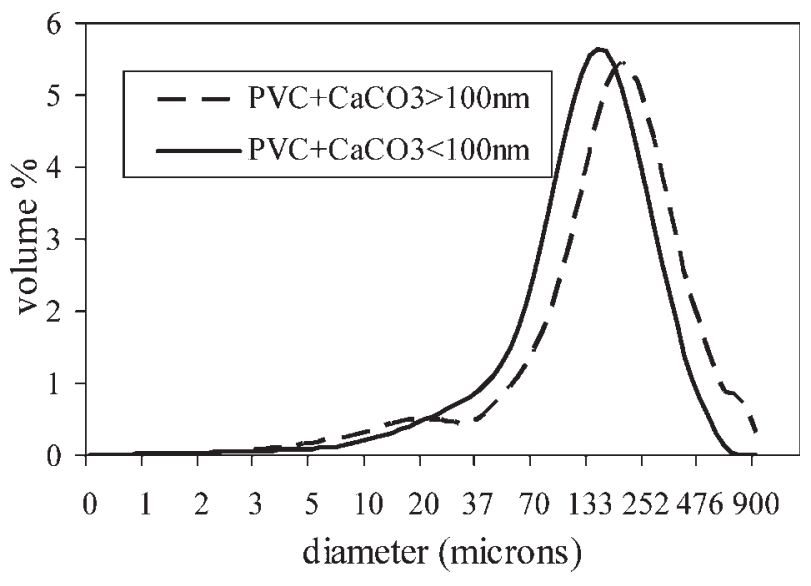

8 Particle size distributions of $\mathrm{PVC}+\mathrm{CaCO}_{3} \quad 5 \% \mathrm{ww} / \mathrm{VC}$ with different UFP sizes

was reached after $40 \mathrm{~min}$. Therefore, the time required to achieve drop stability for the same conditions increases when inorganic particles are added in the organic phase. Before polymerisation, the dispersions have to be stirred until the dynamic steady state is reached to achieve particle size control.

\section{Effect of inorganic particle size}

The properties of the inorganic particles added in the dispersed phase in a dispersion system influence the properties of the phase and consequently, affect the dispersion's dynamic steady state. Particles of different sizes affect the viscosity in a different way resulting in different drop sizes for the dispersed phase as shown in Fig. 7. Smaller particles led to the formation of larger drops, whereas bigger particles led to the formation of smaller drops. The exact opposite effect was observed though, when polymerisation took place as shown in Fig. 8. The addition of smaller inorganic particles led to the formation of smaller PVC grains, whereas the addition of larger inorganic particles led to the formation of larger PVC grains. In the case of the dispersion, the formation of larger drops when smaller inorganic particles are added could probably be explained in terms of the viscosity increase. The smaller inorganic particles may cause the viscosity to increase more than bigger ones, and consequently, higher viscosity leads to larger drops. When a polymerisation reaction takes place though, the larger inorganic particles give rise to forces that are related to their spatial arrangement in the polymer grain. As monomer is absorbed on the inorganic particles and the polymerising PVC chains surround them, bigger $\mathrm{PVC} / \mathrm{CaCO}_{3}$ subgrains are formed for bigger inorganic particles, resulting in bigger PVC grains.

The concentration of the inorganic particles also affects the average drop diameter of the particles. Higher inorganic particle concentrations lead to larger drops. The tendency of the average Sauter mean diameter to increase with increasing inorganic particle loading is shown in Fig. 9. The Sauter mean diameter is defined as a volume surface mean diameter and can be obtained by the following equation

$$
D_{32}=\Sigma N_{\mathrm{i}} d_{\mathrm{i}}^{3} / \Sigma N_{\mathrm{i}} d_{\mathrm{i}}^{2}
$$




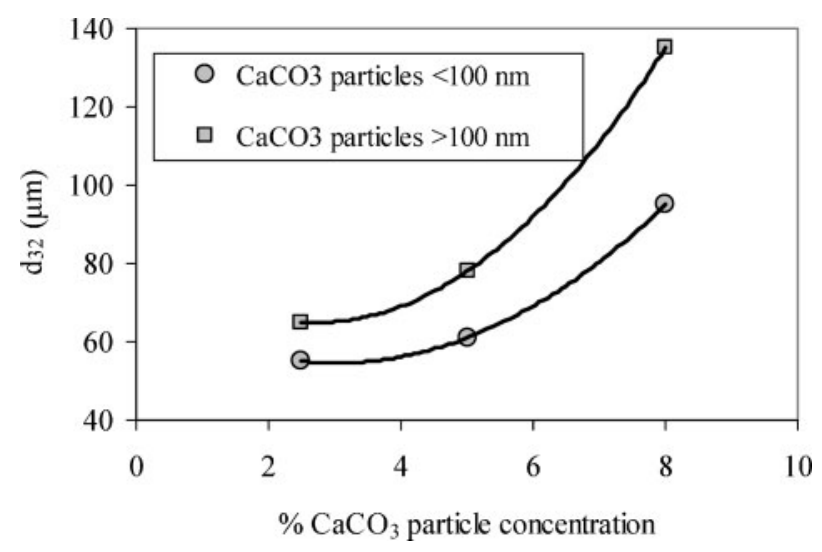

9 Effect of $\mathrm{CaCO}_{3}$ concentration on Sauter mean diameter of trichloroethylene dispersions

\section{Conclusion}

The addition of inorganic UFP in the monomer phase before suspension polymerisation for the production of PVC composites, exerts a strong influence on the initial dispersion and on the dispersed phase drop size distribution. Dispersion of the UFP is required before the water phase is added in the reactor. The time required for the dispersion to reach a dynamic steady state increases when the UFP are added in the monomer phase. The average drop sizes increase in the presence of UFP. The average drop sizes also increase with increasing UFP concentration.

\section{Acknowledgements}

The authors would like to thank EPSRC and INEOS Chlor Vinyls for their support of this work. This paper is based on a contribution to PVC2008, the tenth International PVC Conference, organised by the Polymer Society of the Institute of Materials, Mineral and Mining in Brighton, UK on 22-24 April 2008.

\section{References}

1. L. Zhang, X. H. Chen and C. Z. Li: J. Mater. Sci., 2005, 40, 20972098.

2. F. Gong, M. Feng, C. Zhao, S. Zhang and M. Yang: Polym. Test., 2004, 23, (7), 847-853.

3. X.-L. Xie, Q.-X. Liu, K.-Y. Robert, X.-P. Zhou, Q.-X. Zhang, Z.Z. Yu and Y.-W. Mai: Polymer, 2004, 45, (19), 6665-6673.

4. D. W. Cornwell and G. Rodary: Plast. Rubbers Compos., 2005, 34, (3), 105-110.

5. M. Obloj-Muzaj, M. Zielecka, J. Kozakiewicz, A. Abramowicz, A. Szulc and W. Domanowski: Polimery, 2006, 51, (2), 133-137.

6. M. Zerfa and B. W. Brooks: Chem. Eng. Sci., 1996, 51, (12), 3223 3233.

7. M. Zerfa and B. W. Brooks: Chem. Eng. Sci., 1996, 51, (14), 35913611.

8. Z. P. Wang and B. W. Brooks: Polym. Int., 1993, 30, 317-326. 